\section{Environmental and Genotypic Regulation of Alstroemeria Seed Germination}

\author{
Joseph J. King' and Mark P. Bridgen ${ }^{2}$ \\ Department of Plant Science, U-67, 1376 Storrs Road, University of \\ Connecticut, Storrs, CT 06269
}

Additional index words. scarification, gibberellic acid, potassium nitrate, seed treatments, temperatures, Inca lily, Peruvian lily

\begin{abstract}
Presowing treatments and temperature regimes were tested to improve germination of Alstroemeria hybrids 3 to 12 months following harvest. In addition, seeds from 20 intraspecific $F_{1}$ hybrids of five selections were also tested 3 to 7 or 8 to 12 weeks following harvest. Seeds were pretreated by chipping the seedcoat above the embryo, general abrasion of the entire seedcoat, or soaking 12 hours in distilled water, GA, $(0.029,0.29,2.9 \mathrm{mM})$, or $\mathrm{KNO}_{3}(0.5$ and $1.0 \mathrm{M})$. Pretreatments were evaluated under three environmental regimes: 8 weeks at a constant 18-25C (warm), 4 weeks at 18-25C followed by 4 weeks at 7C (warm-cold), or 4 weeks at $7 \mathrm{C}$ followed by 4 weeks at 18-25C (cold-warm). There was an interaction between pretreatment and environmental regime for percent germination. Germination percentages for the water soak and GA, at 0.29 or $2.9 \mathrm{mM}$ were significantly higher than for the other pretreatments, but were not significantly different from one another. The warm-cold environment yielded higher germination percentages than the other environments. The time to germination was longest for the cold-warm regime. This response depended on the genotype and the age of the seed. Chemical name used: gibberellic acid $\left(\mathrm{GA}_{3}\right)$.
\end{abstract}

Alstroemeria is an excellent cut flower crop having a wide range of flower colors, long vase life, and energy-efficient cultural requirements. Dwarf varieties offer the potential for pot crops as well (Bridgen, 1987). The growing popularity of this species is renewing interest in breeding for novel flower colors, dwarf cultivars, and year-round flowering.

Traditional propagation of Alstroemeria is by division of rhizomes. Seed propagation is uncommon due to variability in the percent germination and the time required for germination. Germination variability may be caused by inviable seeds or improper techniques. Determination of optimum germination conditions could aid breeding efforts and hybrid seed distribution.

Mechanical scarification or "chipping" has been recommended for rapid germination of Alstroemeria seeds (Thompson and Newman, 1979). A commercial seed producer (Park Seed Co., 1987) recommends that seeds

Received for publication 6 Sept. 1988. Storrs Experiment Station Scientific Contribution no. 1257. We thank Fred Meyer of L.R. Meyer, Inc., for donating seed and Robert Langhans, Richard Craig, Ramona Reiser, and Paul Winski for their assistance with this project. This project was funded by the American Floral Endowment, Regional Project NE-168, and Hatch funding. The cost of publishing this paper was defrayed in part by the payment of page charges. Under postal regulaIrons, this paper therefore must be hereby marked advertisement solely to indicate this fact.

${ }^{1}$ Graduate Student. Current address: Dept. of Horticulture, Univ. of Wisconsin, Madison, WI, 53706.

${ }^{2}$ Assistant Professor. To whom reprint requests should be addressed. be imbibed for $12 \mathrm{~h}$ in water, placed in moist media at $20 \mathrm{C}$ for $\approx 4$ weeks, and then transferred to $7 \mathrm{C}$ for 4 weeks. Germination and seedling development then proceed rapidly after return to higher temperatures.

Gibberellins have been used extensively in seed propagation to substitute for cold requirements in dormant seeds (Corns, 1959; Norton, 1985; Spicer and Dionne, 1961), to increase germination rates (Nagao and Furutani, 1986), to stimulate seedling growth, and to overcome dwarfing of dormant epicotyls (Hartman and Kester, 1975). Nitrate is another germination promoter (Wilkins, 1984); when potassium nitrate is applied as regimes.

* Significant at $P=0.05$. a 10 to $20-\mathrm{mm}$ solution to the substrate surrounding dormant seeds (Hartman and Kester, 1975) or as a 1-M presowing soak, increased germination percentages and reduced germination times have been observed (Barton, 1965; Nagao and Furutani, 1986).

The objectives of this study were to determine the influence of presowing treatmerits, genotype, and temperature on the germination of Alstroemeria seeds.

Hybrid Alstroemeria seeds obtained from Fred Meyer of Escondido, Calif., were used in all pretreatment and temperature experiments. These seeds were tested 3 to 12 months after harvest. Experiments were factorial in design, with eight presowing treatments and three temperature regimes tested. There were four replications per treatment, each with 18 seeds. The presowing treatments were a 12$\mathrm{h}$ imbibition of distilled water; imbibition followed by chipping the seedcoat to expose the underlying embryo (accomplished by gently cutting the small bump opposite to the brown or black scar of the hilum); general seedcoat abrasion with sandpaper to expose the embryo, followed by imbibition; $\mathrm{GA}_{3}$ at $0.029,0.29$, or $2.9 \mathrm{~mm}$ followed by 12-h imbibition; and potassium nitrate $\left(\mathrm{KNO}_{3}\right)$ at 0.5 or $1.0 \mathrm{M}$ followed by $12-\mathrm{h}$ imbibition.

Dry seeds were washed in $3.94 \%$ sodium hypochlorite $(\mathrm{NaOCl})$ with 0.19 Tween-20 for $15 \mathrm{~min}$ then rinsed three times in sterile distilled water. Seedcoat abrasion was applied to dry seeds before washing, other treatments were given after washing.

General seedcoat abrasion was accomplished by placing dry seeds into a $90 \times 10$ $\mathrm{mm}$ glass petri dish with a magnetic stir bar on a stir plate. A cylinder of sandpaper (\#80) was then placed over the petri dish and seeds. The stir plate was set at medium speed and allowed to run for $2 \mathrm{~h}$. Seeds were then washed by the procedure described above and imbibed in distilled water for $12 \mathrm{~h}$

Seeds were sown in Fafard \#2 soilless medium (Conrad Fafard, Springfield, Mass.)

Table 1. Days to germination of Alstroemeria seeds following various pretreatments and temperature

\begin{tabular}{|c|c|c|c|c|}
\hline \multirow[b]{2}{*}{ Pretreatment } & \multicolumn{3}{|c|}{ Temp regime } & \multirow[b]{2}{*}{ Mcans } \\
\hline & Warm & Warm-cold & Cold-warm & \\
\hline Waler & 27.1 & 33.4 & 46.0 & 35.5 \\
\hline Chipping & 19.9 & 17.7 & 39.3 & 25.6 \\
\hline \multicolumn{5}{|l|}{$\mathrm{GA}_{3}(\mathrm{mM})$} \\
\hline 0.029 & 29.8 & 33.0 & 47.6 & 37.1 \\
\hline 0.29 & 26.4 & 31.8 & 49.4 & 35.9 \\
\hline 2.9 & 28.7 & 29.9 & 45.6 & 34.7 \\
\hline \multicolumn{5}{|l|}{$\mathrm{KNO}_{3}(\mathrm{M})$} \\
\hline 1.0 & 25.9 & 27.1 & 51.2 & 34.7 \\
\hline 0.5 & 25.0 & 27.5 & 49.4 & 33.9 \\
\hline Mcans ${ }^{x}$ & $30.6 \mathrm{~b}$ & $32.7 \mathrm{~b}$ & $48.3 \mathrm{a}$ & \\
\hline \multicolumn{5}{|c|}{ Significance of $F$ ratio } \\
\hline Pretrcaiment (P) & & & & - \\
\hline Environmen! (E) & & & & - \\
\hline$P \times E$ & & & & - \\
\hline
\end{tabular}

${ }^{\mathrm{z}}$ Warm $=$ constant $18-25 \mathrm{C}$ for 8 weeks, warm-cold $=4$ weeks at $18-25 \mathrm{C}$ followed by 4 weeks at $7 \mathrm{C}$, cold-warm $=4$ weeks at $7 \mathrm{C}$ followed by 4 weeks at $18-25 \mathrm{C}$.

${ }^{\mathrm{y}}$ Pretreatment means separation by least significant difference at $P=0.05$; LSD $=6.1$

${ }^{x}$ Environment treatment means separation by Duncan's multiple range test, $P<0.05$. 
Table 2. Percent germination of Alstroemeria seeds for various pretreatments and temperature regimes.

\begin{tabular}{|c|c|c|c|c|}
\hline \multirow[b]{2}{*}{ Pretreatment } & \multicolumn{3}{|c|}{ Temp regime ${ }^{x}$} & \multirow[b]{2}{*}{ Means ${ }^{y}$} \\
\hline & Warm & Warm-cold & Cold-warm & \\
\hline Water & 86.1 & 90.3 & 81.9 & $86.1(109.3$ \\
\hline Chipping & 40.3 & 69.4 & 56.9 & $55.5 \quad(59.9$ \\
\hline Gencral abrasion & 1.4 & 2.7 & 4.2 & $2.7 \quad(2.7)$ \\
\hline \multicolumn{5}{|l|}{$\mathrm{GA}_{3}(\mathrm{mM})$} \\
\hline 0.029 & 83.3 & 77.7 & 65.3 & $74.4 \quad(86.8$ \\
\hline 0.29 & 86.1 & 86.1 & 69.4 & $80.4 \quad(96.3$ \\
\hline 2.9 & 84.7 & 88.8 & 73.6 & $82.5 \quad(99.4$ \\
\hline \multicolumn{5}{|l|}{$\mathrm{KNO}_{3}(\mathrm{M})$} \\
\hline 1.0 & 81.9 & 83.3 & 65.3 & $76.8 \quad 189.4$ \\
\hline 0.5 & 68.0 & 86.1 & 65.3 & $73.1 \quad(84.2$ \\
\hline Means ${ }^{x}$ & $66.5 \mathrm{~b}$ & 73.8 a & $60.2 c$ & \\
\hline \multicolumn{5}{|c|}{$\begin{array}{l}\text { Significance of } F \text { ratio } \\
\text { from analysis of variance }\end{array}$} \\
\hline Pretrcaiment (P) & & & & - \\
\hline Environment (E) & & & & - \\
\hline$P \times E$ & & & & NS \\
\hline
\end{tabular}

${ }^{\mathrm{z}} \mathrm{Warm}=$ constant $18-25 \mathrm{C}$ for 8 weeks. warm-cold $=4$ weeks at $18-25 \mathrm{C}$ followed by 4 weeks at $7 \mathrm{C}$, cold-warm $=4$ weeks at $7 \mathrm{C}$ followed by 1 weeks at $18-25 \mathrm{C}$.

${ }^{y}$ Pretreatment means separation by least significant difference at $P=0.05$ : LSD $=13.2$. Analyses performed on arcsin-transformed values. Arcsin-transformed percentages arc shown in parenthesis. ${ }^{x}$ Environment treatment means separation by Duncan's multiple range test, $P<0.05$. Original data presented. Analyses performed on arcsin-transformed values.

, Not significant or significant at $P=0.05$, respectively.

Table 3. Average percent germination of 20 Alstroemeria intraspecific $F_{1}$ hybrids.

\begin{tabular}{|c|c|c|c|c|}
\hline \multirow{2}{*}{$\begin{array}{c}\text { Parent of } \\
\text { cross }\end{array}$} & \multicolumn{4}{|c|}{ Seed age following harvest (weeks) } \\
\hline & \multirow{2}{*}{$\frac{3-\gamma}{\text { After coldw }}$} & \multicolumn{3}{|c|}{$8-12$} \\
\hline$\overline{\text { Seed } \times \text { pollen }}$ & & Bcfore cold $x$ & After $c$ & old \\
\hline $3 \times 7$ & $0 \quad c$ & $11.1 \mathrm{~cd}$ & 0 & b \\
\hline $3 \times 10$ & $0 \mathrm{c}$ & $53.4 b c$ & 0 & b \\
\hline $3 \times 14$ & $0 \mathrm{c}$ & $60.9 \mathrm{~b}$ & 0 & $\mathrm{~b}$ \\
\hline $3 \times 26$ & $11.1 \mathrm{~b}$ & $90.7 \mathrm{a}$ & 0 & b \\
\hline $7 \times 3$ & $0 \mathrm{c}$ & $71.8 \mathrm{~b}$ & 0 & b \\
\hline $7 \times 10$ & $0 \mathrm{c}$ & $33.3 \mathrm{c}$ & 11.1 & a \\
\hline $7 \times 14$ & $22.2 \mathrm{a}$ & $88.4 \mathrm{a}$ & & $b$ \\
\hline $7 \times 26$ & $0 \mathrm{c}$ & $83.3 \mathrm{a}$ & 0 & b \\
\hline $10 \times 3$ & $0 \quad \mathrm{c}$ & $63.3 \mathrm{~b}$ & 3.3 & b \\
\hline $10 \times 7$ & $0 \quad c$ & $53.9 b c$ & 0 & b \\
\hline $10 \times 14$ & $33.3 \mathrm{a}$ & $78.6 \mathrm{ab}$ & 0 & $b$ \\
\hline $10 \times 26$ & $27.8 \mathrm{a}$ & $83.7 \mathrm{a}$ & 2.0 & b \\
\hline $14 \times 3$ & $0 \mathrm{c}$ & $0 d$ & 0 & b \\
\hline $14 \times 7$ & $11.1 \mathrm{~b}$ & $25.0 \mathrm{c}$ & 0 & $b$ \\
\hline $14 \times 10$ & $0 \quad c$ & $0 d$ & 0 & $b$ \\
\hline $14 \times 26$ & $0 \mathrm{c}$ & $64.4 b$ & 0 & b \\
\hline $26 \times 3$ & $31.3 \mathrm{a}$ & $0 d$ & 0 & $b$ \\
\hline $26 \times 7$ & $25.0 \mathrm{a}$ & $0 d$ & 0 & b \\
\hline $26 \times 10$ & $13.3 \mathrm{~b}$ & $0 d$ & 0 & b \\
\hline $26 \times 14$ & $11.1 \mathrm{~b}$ & $33.3 \mathrm{c}$ & 0 & $b$ \\
\hline
\end{tabular}

${ }^{\mathrm{z}}$ Mean separation within columns by Duncan's new multiple range test, $P=0.05$.

${ }^{\mathrm{y}}$ None germinated after 4 weeks at $18-20 \mathrm{C}$; i.e., before the cold treatment.

${ }^{\mathrm{x}}$ After 4 weeks at $18-20 \mathrm{C}$.

${ }^{\mathrm{w}}$ After 4 weeks at $18-20 \mathrm{C}$ followed by 4 weeks at $7-10 \mathrm{C}$.

in $76.5 \times 45-\mathrm{mm}$ plastic cell paks $(\# 806$ Milikowski Co., Stafford Springs, Conn.) after pretreatment. All presowing treatments were evaluated in three environmental regimes: 1) Constant 18-25C (warm) for 8 weeks, 2) 4 weeks at $18-25 \mathrm{C}$ followed by 4 weeks at 7C (warm-cold), 3) 4 weeks at 7C followed by 4 weeks at 18-25C (cold-warm). The 18-25C environment was maintained in a greenhouse and the $7 \mathrm{C}$ environment was in a walk-in refrigerator.

Data were collected for percent germination and days to germination. Successful germination was noted on the day a seedling penetrated the surface of the growing medium. After 10 weeks from sowing, the germination test was concluded. Arcsin-
Greenhouses, Ithaca, N.Y., during Summer 1988. and seeds were collected during August. Seeds from these 20 intraspecific hybridizations were germinated with the warm cold procedure either 3-7 or 8-12 weeks after harvest; $12-75$ seeds per hybrid were tested.

A significant interaction occurred between pretreatment and environmental regime for days to germination (Table 1). All pretreatments, except general abrasion, delayed germination in the cold-warm environment relative to the warm or warm-cold environments. The cold-warm environment delayed germination $\approx 17$ days over the other temperature combinations. The chipping treatment speeded and the general abrasion slowed germination the most.

Presowing treatments caused variable responses in germination percentages. Imbibition in distilled water or $\mathrm{GA}_{3}$ at 0.29 or $2.9 \mathrm{~mm}$ yielded the highest germination percentages (Table 2), but the addition of GA, offered no advantage over imbibition in water. The mechanical scarification treatments, chipping and general seedcoat abrasion, reduced seedling emergence.

Environmental variables caused distinct differences in percent germination. The warm-cold regime yielded $\approx 7 \%$ to $14 \%$ higher germination percentages than the others (Table 2). While some seeds germinate under warm conditions, others require a cold period to overcome dormancy; these data indicate that Alstroemeria seeds may possess various degrees of dormancy.

Although chipping offered the advantage of faster germination, the advantage was offset by poor germination percentages. Poor germination in both scarification treatments was related to loss of seeds to medium- or seed-borne pathogens. Damping-off symptoms, such as soft seeds or hollow seedcoats, were common among ungerminated seeds in this treatment. These conditions could be eliminated in a completely aseptic germination environment. The general abrasion treatment damaged the embryos or seeds. Alternative approaches to removing the seedcoat may also alleviate this problem. Experiments in our laboratory with soaks in $18.8 \mathrm{~N}$ sulfuric acid or $8.2 \mathrm{~N}$ hydrochloric acid showed that acid pretreatments strongly inhibited germination.

Seeds older than 12 weeks following harvest require the warm-cold treatment to achieve the maximum germination percentage. Although embryos are mature, the seedcoats prevent germination. The conclusion that the seedcoat inhibits germination is supported by faster germination with chipping treatments. The increased germination of the warm-cold treatment suggests that there are physiological factors in the seedcoat that are responsive to cold stratification or that time is required for softening of the seedcoat. Seeds sown 8 to 12 weeks after harvest may be mature, but in a state in which dormancy is not fully inactivated, thereby explaining germination in the warm environment.

Germination experiments with the 20 intraspecific hybrids demonstrate that genotype affects embryo development and that 
embryo development continues after seeds are harvested.

Seeds sown 3 to 7 weeks after harvest had very poor germination after the warm-cold treatment, and none germinated before they were held at low temperature. However, many seeds sown 8 to 12 weeks after harvest germinated before the cold treatment was administered (Table 3). Only nine of the 20 intraspecific hybrids sown 3 to 7 weeks after harvest germinated after the warm-cold treatment. Germination ranged from $11 \%$ to $33 \%$. Of the 20 intraspecific hybrids sown 8 to 12 weeks after harvest, 15 germinated before the cold treatment was administered. with germination ranging from $11 \%$ to $91 \%$. and four crosses germinated after the cold treatment. It appears that embryo development continues for 8 to 12 weeks after harvest. If seeds are sown before that time, germination is reduced due to embryo immaturity.

There also appear to be genotypic effects on embryo development. In seeds sown 3 to 7 weeks from harvest, germination percentages for seed parents ranged from $11 \%$ to $33 \%$ for those that germinated (Table 3 ). The highest germination value was for selection \#26 when it was the seed parent; this advantage for \#26 disappeared when it was the pollen parent. In seeds sown 8 to 12 weeks from harvest, selection \#26 as the seed parent appeared to inhibit germination, but it had a tremendous promoting effect when used as the pollen parent.

Genotypic and physical constraints, morphologically immature embryos, and possible physiological inhibitors in the seedcoats appear to cause a combined dormancy in Alstroemeria seeds. Further experiments are required to elucidate the time course of embryo maturation, dormancy initiation, and dormancy breaking.

The observations in this study indicate that if morphologically immature embryos are allowed to develop for 8 to 12 weeks after harvest, optimum germination will occur if seeds are soaked $12 \mathrm{~h}$ in water and then subjected to 4 weeks in a warm environment (18-20C). Seeds older than 12 weeks from harvest require an additional 4 weeks in a cold environment (7-10C) to overcome constraints of the seedcoat and associated physiological factors.

\section{Literature Cited}

Barton, L.V. 1965. Seed dormancy general survey of dormancy types in seeds, and dormancy imposed by external agents. Encyclopedia Plant Physiol. 15(2):699-720.

Bridgen, M.P. 1987. Scheduling Alstroemeria as a six inch pot crop. Conn. Greenhouse Nwsl. 137:8-9.

Corns, W.C. 1959. Effect of gibberellin treatments on germination of various species of weed seeds. Can. J. Plant Sci. 40:47-51.

Hartman, H.T. and D.E.-Kester. 1975. Plant propagation: Principles and practices. 3rd cd. Prentice Hall, Englewood Cliffs, N.J. p. 146180.

Nagao, M. and S.C. Furutani. 1986. Improving germination of papaya seed by density separation, potassium nitrate, and gibberellic acid. HortScience 21(6):1439-1440.
Norton, C.R. 1985. Seed germination of Rhus typhina (L). after growth regulator treatment. Plant Propagator 32(2):5.

Park Seed Co. 1987. Germination recommendations for Alstroemeria seed. George W. Park Seed Co., Greenwood, S.C.

Spicer, P.B. and L.A. Dionne. 1961. Use of gib- berellin to hasten germination of Solanum seed. Nature 189(4761):327-328.

Thompson, P.A. and P. Newman. 1979. Germination of Alstroemerias. The Garden 104(2):7576.

Wilkins, M.B. 1984. Advanced plant physiology. Pitman Publishing, London. p. 450 